\title{
A Biologia do Comportamento e a Sala de Aula
}

\author{
The Biology of Behavior and the Classroom
}

\author{
DCarmen Érica Lima de Campos Gonçalves ${ }^{1}$ \\ Amarildo Menezes Gonzaga² \\ ${ }^{1}$ Instituto Federal de Educação, Ciência e Tecnologia do Amazonas (IFAM) Manaus Centro, Manaus, AM, Brasil. \\ Autora Correspondente: 2018129750038@ifam.edu.br \\ ${ }^{2}$ Instituto Federal de Educação, Ciência e Tecnologia do Amazonas (IFAM) Manaus Centro, Programa de Pós-Graduação em \\ Ensino Tecnológico, Manaus, AM, Brasil.
}

Resumo: Diante da problemática de que valor temos atribuído às emoções no ensino mediador, este trabalho objetiva trazer as potencialidades da Etologia (de Darwin a Ekman) na prática da sala de aula como estratégia docente, pelos objetivos específicos: (a) revelar a leitura da expressão das emoções a fim da receptividade do alunado; (b) indicar seu uso no desenvolvimento (auto)formativo dos professores; (c) propor, a partir dessa utilização, a readequação da prática professoral na mediação da aprendizagem, tal qual Jung descreve a Educação pelo Exemplo. O corpus foi construído a partir de dois eventos de extensão em instituições públicas de graduação e de pós-graduação, triangulado com o registro escrito dos participantes pela abordagem fenomenológico-empirista de Jung, por uma análise hermenêutica estrutural sobre unidades significativas, dos quais dois casos são trazidos aqui, a fim de revelar as possibilidades de reflexão (auto)formativa, a partir dos conteúdos emergidos como pesquisa-formação docente continuada.

Palavras-chave: Prática docente; Emoções; Psicologia do comportamento; Etologia.

\begin{abstract}
Given the problem of what value we have attributed to emotions in teaching processes, this research aims to bring the potential of ethology (from Darwin to Ekman) in the practice of the classroom as a teaching strategy; with these specific objectives: (a) to reveal the reading of the expression of emotions with a view to students' responsive behavior; (b) to indicate its use in teachers' (self) development; (c) to propose, based on this use, the adjustment of teaching practice in the mediation of learning, as described by Jung in The Education by Example. The corpus was built from two extension events in public institutions, at undergraduate and graduate levels; and triangulated with the written records made by the participants, according to Jung's phenomenological-empirical approach, with structural hermeneutic analysis of units. Two cases are addressed in this paper in order to reveal the possibilities of (self) reflection based on the emerging contents as continuing teacher education research.
\end{abstract}

Keywords: Teaching practice; Emotions; Psychology of behavior; Ethology. 


\section{Introdução}

Temos vivido nas últimas décadas um movimento na compreensão da sala de aula e, por conseguinte, da formação de professores a partir não apenas de métodos, fórmulas e conteúdos, mas do percurso experienciado.

Nesse cenário, problematizamos qual relevância tem sido atribuída às emoções ao pensarmos como se formou o ser que enveredou pelo caminho da docência, e como essas escolhas afetaram decisões e atuações no exercício dessa docência.

O que trazemos aqui é um desdobramento dessas investigações, considerando a pesquisa-formação para a formação contínua e continuada como aquela que busca averiguar o fenômeno e, portanto, os matizes não quantificáveis da influência das emoções, percebendo o quanto elas estão atreladas àquelas decisões tidas como meramente escolhas racionais, dando ainda relevo ao impacto deste conteúdo em sala de aula.

Com o propósito de refletirmos sobre esses percursos, nos localizamos na visão maslowniana de que, supridas as necessidades básicas, seguimos às nossas interações socioemocionais e destas, para o que podemos chamar de conhecimento de si a partir de conhecimentos mais amplos que respondem e ressignificam questões existenciais que retroalimentam nossas ações diárias, inclusive as profissionais.

Assim problematizamos: que valor temos atribuído para questões não densamente valorizadas, como as emoções em nossa prática docente? Para responder a isso, nos dedicamos a reunir os elementos da biologia do comportamento - de Darwin a Ekman -, que abordam as emoções, conforme o desenho do escopo da pesquisa descrito a seguir.

O objetivo principal é trazer as potencialidades da Etologia (de Charles Darwin a Paul Ekman) no exercício docente para professores em formação inicial e continuada, como estratégia docente. Para tal, desenvolvemos os seguintes objetivos específicos:

a. revelar a leitura da expressão das emoções a fim da receptividade dos participantes;

b. indicar seu uso para o desenvolvimento (auto)formativo continuado docente e;

c. propor, a partir dessa leitura, a readequação de atitudes e ações com os discentes em prol do desenvolvimento de relações harmônicas.

O que se justifica como contribuinte ao movimento mediativo do ensino e da aprendizagem, tal qual Carl Gustav Jung descreve, é a Educação pelo Exemplo.

Vamos discorrer de maneira ampla a ciência da leitura das emoções, para então expor duas situações amostrais em que a leitura da linguagem e do comportamento não verbais foram utilizadas como estratégia docente.

No final, reiteraremos a importância deste tipo de leitura como coadjuvante à prática docente, a fim de estabelecer relações mais harmoniosas, que reforcem e ampliem as dimensões de senso de coletivo e de comunidade em nossa sociedade a partir dos nossos alunos.

Nossos estudos se justificam como triangulação da prática de construção do produto educacional oriundo de nossa pesquisa no mestrado profissional em Ensino Tecnológico, através do qual foi aprofundado o sentido das unidades significativas emergidas em uma atividade de extensão para formação de professores, embasada no uso no uso da Pesquisa Biográfica e de Narrativas. 
Porém, os resultados foram promissores para trazermos à reflexão a utilidade de considerarmos e aprendermos sobre a biologia do comportamento e suas contribuições na sala de aula, uma vez que essas indicaram que, se aquele que ministra percebe o que está além dos (auto)filtros conscientes, ou não, dos que participam de sua aula, as chances de abordagem para mediação dos conteúdos de ensino e aprendizagem podem ser exponenciadas.

\section{A Ciência da Expressão das Emoções}

Há mais de quarenta anos, Paul Ekman (EKMAN, 2012) tem estudado a expressão das emoções inatas, tais como: alegria, tristeza, angústia, raiva, surpresa, medo, desgosto, nojo e desprezo, e os processos biológicos envolvidos na ocorrência delas, assim como suas respostas fisiológicas universais que se expressam em até 4 (quatro) segundos.

Tal ocorrência dá-se por meio de um disparo inconsciente, a partir do sistema límbico, e desencadeia uma descarga hormonal que atinge a musculatura facial e corporal, dividindose em três fases: início, ápice e regressão; não podendo ser dissimulada conscientemente em função das ocorrências musculares e suas janelas temporais (PAUL EKMAN GROUP, 2019).

Em razão dessas particularidades da expressão e suas consecutivas respostas fisiológicas, mais evidenciadas por meio gestual e/ou fônico, a leitura desses canais indica tentativas de dissimulação, pelas medidas construídas no Facial Action Coding System (FACS), as chamadas Action Units (AU) (EKMAN; ROSENBERG, 2005).

Como as descargas hormonais próprias a cada emoção são descarregadas no sangue, toda a musculatura do corpo responde em grau próprio à presença e à intensidade destas substâncias na corrente sanguínea, disparando movimentos musculares nos membros superiores, inferiores, torso, quadril, tórax, ombros, observados a partir da cinésica, proxêmica, háptica, postura, vestimenta e adornos (NAVARRO; KARLINS, 2008).

Tais evidências podem ser atestadas pelo protocolo SCAns (Six Channel Analysis), que considera a veracidade de uma emoção, se estão presentes em, ao menos, três ou quatro canais de comunicação não verbal (LANSLEY, 2017).

Entre eles podem ser citados: estilo interacional, voz, conteúdo associado à verbalização, expressões faciais anômalas à linha de base do indivíduo, linguagem corporal, e psicofisiologia - já atestados em exames de escaneamento do comportamento fisiológico neural, como citam Navarro e Karlins (2008) e Boisvert (2019).

De acordo com Lansley (2017), o conteúdo expresso verbalmente é comparável ao que vemos em um iceberg, já que, na parte submersa, é onde são percebidas a maior parte destes outros canais - fluxo, evasão e gerenciamento das expressões, volume, timbre e tom vocais, evasão no conteúdo expresso, tensão muscular, distanciamento corporal, checagem no outro do efeito da própria declaração, deslizes verbais/atos falhos, uso de músculos impróprios para simulação de uma emoção com alteração do tempo de duração e falta de simetria e sincronia; deslizes gestuais, ilustradores, manipuladores, não visualização, etc.

Porém, a prática dissimulativa incorre em um enorme gasto energético no processo cognitivo, ocasionando clusteres nas expressões e vazamentos naturais impossíveis de serem gerenciados em tempo real a fim da disrupção ante a avaliação do destinatário da mensagem (EKMAN; FRIESEN, 2003). 
Em outras palavras, há um inevitável sequestro de energia cognitiva pelo sistema emocional, haja vista que depreender cada minúscula reação exige muito mais do que aquilo que o reflexo emocional autônomo está evolutivamente habituado a realizar a partir da herança evolutiva universal da expressão natural das emoções (DARWIN, 2009).

Tudo isso incorre em alterações cardiorrespiratórias, de fala, do sistema digestório, da oculésica e outros canais (Points of Interest - PINs) gerenciados pelo Sistema Nervoso Autônomo, das quais ao menos três ou quatro são passíveis de serem notadas pelo observador treinado, que detectará inconsistência no $A B C$ (Account, Baseline, Context), ou seja, no relato, na linha de base e no contexto (LANSLEY, 2017).

Soma-se ainda a ressalva dada por Ekman (2012), que nos chama a atenção para a conduta dissimulativa que, segundo ele, não precisa ter necessariamente a compreensão de que seja mentira ou engodo, mas a tentativa de imprecisar as informações prestadas em situações nas quais não há acordo consensual quanto ao uso da dissimulação (como o seria em brincadeiras ou jogos que façam uso de blefe) para, por exemplo, evitar danos.

Tentativas de dissimulação, tanto quanto a expressão das emoções, estão vinculadas a gatilhos herdados evolutivamente, ou em nossa própria experiência de vida (EKMAN, 2012; LANSLEY, 2017).

Portanto, aqui há um aprendizado para a formação de professores: reconhecer esses gatilhos em si e em seus docentes é a chave para a administração pessoal e a melhoria das relações de mediação do ensino e da aprendizagem em sala de aula, pois permite redirecionar algum comportamento ou fala para um contexto que apazigue ou cesse alguma emoção disruptiva ao conteúdo e à intencionalidade do conteúdo que está sendo ministrado.

Portanto, a compreensão da expressão das emoções e da conduta dissimulativa foram de grande valia para confrontar os conteúdos escritos dos participantes (tempo para elaborar, treinar, pensar, filtrar o conteúdo que se desejou revelar), com suas linguagens e comportamento não verbais.

Já que a conduta emocional é via de mão dupla quanto à influência, de dentro para fora e de fora para dentro, como afirmam Ekman (2012) e Cuddy (2012, 2016), permite o (auto)gerenciamento que oportunize comportamentos conciliadores que favoreçam o desenvolvimento e o fortalecimento do senso de comunidade e de coletivo.

No conjunto de aspectos a serem observados, Navarro e Karlins (2008) apontam piscar, tapar os olhos, desviar o olhar, linguagem comportamental contraditória à verbal, movimentos de superioridade (de cima para baixo), como tentativas de evitação e imposição para evitar o conteúdo tido por danoso pelo indivíduo, de maneira consciente, subconsciente ou inconsciente, que vazam em decorrência do cognitivo estar muito concentrado em dissimular a face, com o sistema límbico (emoção) preponderando sobre o córtex pré-frontal (razão) nessas áreas do corpo.

Destaca-se que o estudo da expressão das emoções já era objeto de pesquisa para Darwin em 1872, que, sem os recursos dos escaneamentos de imagem neural e outras técnicas de averiguação atuais, dispôs sobre o tema a partir de, aproximadamente, trinta observações localizadas nos mais diversos e distantes lugares na Europa, África e algumas colônias americanas, de forma que abrangeu diversos povos e construções sociais distintos, prevalecendo as mesmas reações para as mesmas emoções (DARWIN, 2009). 
Tal observação também foi sustentada por Ekman (2012), que percebeu que, mesmo os povos sem verbete idiomático para descrever tal ou qual emoção, atestavam as expressões a partir dos contextos e das descrições de quem as vivia e de seus pares.

Para Darwin (2009), o envolvimento da musculatura estava associado a processos de recompensa localizados no sistema nervoso e de efeito social. O uso da expressão de medo, por exemplo, quando um hominídeo não podia representar o mesmo sentimento a seu par por meio de grito ou qualquer outra expressão que gerasse som. Agindo assim, alertava-o do risco de algum predador não visto, preservando a si e a seu o grupo, pois mantinha a salvo mais um membro para caça, coleta, defesa, procriação.

O medo sentido pela presença do predador, ou pelo risco de perder um dos seus, agia sobre o sistema vasomotor para fuga ou para rendição, sendo que, por exemplo, para fuga, quanto menos energia estivesse envolvida no metabolismo da digestão, mais energia e concentração sanguínea nos membros para correr. Tal situação também já havia sido percebido por Darwin quando este dizia que "[...] os mais complexos movimentos podem ser executados sem o menor esforço e consciência" (DARWIN, 2009, p. 33) e: "[...] o sistema vasomotor, que regula o diâmetro das pequenas artérias, é diretamente modulado pelo sensório, como percebemos quando um homem enrubesce de vergonha." (DARWIN, 2009, p. 66).

Tais conceitos, se levados à sala de aula, nos obriga a perceber que as alterações fisiológicas dos participantes podem dar ao docente tempo e alternativas para redirecionar sua atitude ou sua fala, de modo a aproximar o aluno do conteúdo que se quer abordar.

Assim como perceber intencionalidades interferentes ao processo de ensino e de aprendizagem, é possível ainda verificar indicações do nível de interação real da turma com o conteúdo através da receptividade que apresentem, só para citar alguns exemplos.

No caso dessa pesquisa, em uma de nossas práticas docentes nas quais abordamos junto a uma turma de licenciandos em química de uma instituição pública, comportamentos contributivos a um jovem pesquisador em relação à construção de seus trabalhos de conclusão de curso, observamos um gesto indicador de desprezo e silêncio, além do comportamento de evitação, juntamente com expressão facial de desprezo e afastamento verbal e corporal, em um aluno.

Como era uma aula-convite, passamos, então, a pontuar os elementos da aula e verificar, ao mesmo tempo, as reações do aluno em questão. Notamos que as abordagens de pesquisa eram um gatilho para aquele comportamento. Rapidamente passamos a pedir aos alunos que relatassem suas experiências com a pesquisa acadêmico-científica, o que levou os outros alunos a apontarem para aquele, como sendo o que mais tinha experiência, por ter participado de Programa de Iniciação Científica.

Ali tivemos duas percepções: a visão empobrecida de que ciência só se faz em laboratórios fechados, com jaleco, e a de que essa situação transformou-se em uma oportunidade de desconstruir essa visão a partir do próprio conteúdo emergido na fala do aluno e nas problematizações que incitamos, considerando que a pesquisa em Licenciatura pede entrelaçamento a projetos na interface Ensino-Educação.

Além de, em alguns minutos desarmarmos aquele aluno, trazendo-o para envolverse com a aula, também a sua experiência contribuiu com a discussão dos demais, elevando o nível de interação entre os discentes e a receptividade com a aula, na qual enfocávamos outras abordagens, além da quantitativa. 
Dando movimento e construção durante a mediação pela participação efetiva de todos, percebemos que a oportunidade de contar de si o fez se aproximar e demonstrar interesse, pois nossa experiência também havia atravessado pelos mares que ele navegara na iniciação científica.

Porém, não nos detivemos ali e ampliamos as possibilidades de construção do conhecimento dentro do panorama acadêmico-científico. Este é um exemplo prático das possibilidades de harmonização em sala de aula, quando utilizamos a leitura etológica em nossa prática docente.

Para mais, sugerimos ao leitor interessado que busque as referências que aqui utilizamos para aprofundar seu conhecimento quanto às expressões das emoções, haja vista não termos espaço aqui para detalhar mais pormenorizadamente.

\section{Da Prática Experenciada e sua Análise}

A utilização da leitura da expressão das emoções como estratégia avaliativa foi realizada a fim de triangular com o corpus, construído a partir do registro escrito de participantes de um colóquio utilizado como estratégia formativa quanto aos conteúdos emergidos após a prática, e confrontar estes escritos com as emoções vivenciadas durante a atividade de extensão supracitada, a fim de perceber se os filtros pessoais dos participantes haviam influenciado seus registros.

A verificação era necessária para checar a receptividade dos participantes quanto a conteúdos pedagógicos que apontavam para a importância da (auto)formação continuada, enquanto professores atuantes ou em formação.

Em outras palavras, desejávamos averiguar como era recebido pelos participantes o pensar o conhecimento de si enquanto contribuinte-interferente da prática docente. Porém, o registro escrito era passível de ser refletido antes, colocando filtros do que se gostaria ou não que fosse lido, além de haver a possibilidade de ser tido como uma avaliação que exigisse uma resposta certa.

Desta forma, a leitura da expressão das emoções no registro filmado do colóquio como estratégia formativa poderia revelar o quanto do registro escrito havia sofrido filtros dos participantes.

Para as filmagens, os participantes receberam o debriefing nos termos de Shaughnessy; Zeichmeister e Zeichmeister (2012), onde a atividade foi classificada como Natural e Pública, sem perguntas de desabono à integridade dos participantes (o registro escrito era livre formulário não estruturado - a partir de uma única pergunta: o que aprendemos hoje?). A adesão era livre e com a possibilidade de desistência, além do anonimato, e disponibilidade de contato posterior para acompanhamento do tratamento dado ao conteúdo, enquanto pesquisa acadêmico-científica.

Houve duas amostras, compostas por 13 registros a primeira (entre 15 presentes) e de 45 registros a segunda; ambas ocorridas em atividades de extensão de instituições públicas de nível superior e com pós-graduação na área de Ensino (formação inicial e continuada), de livre acesso aos interessados após inscrição nos eventos, cientes da programação antecipadamente, e com opção de participação nas atividades de interesse. 
Esses eventos eram públicos e abertos, voltados para professores em formação inicial ou continuada, em exercício ou discentes de cursos relacionados, dos quais participaram majoritariamente professores, servidores e alunos das instituições ofertantes, professores das secretarias de educação municipal (SEMED) de Manaus, e estadual (SEDUC) do Amazonas.

O cenário era um Colóquio que trazia as contribuições pedagógicas da professora pesquisadora amazônida lerecê dos Santos Barbosa, utilizando como pretexto seu romance literário O Leilão (BARBOSA, 2015), a partir da lente da psicologia junguiana. Isso para pensar o Processo de Individuação a fim da Educação pelo Exemplo, uma vez que, como identificado no levantamento realizado, a narrativa trazia projeções da história de vida da autora sujeito da pesquisa (GONÇALVES, 2020).

Em sua história de vida e (auto)formação, lerecê superou a dislexia, além de um incêndio em sua casa, na infância, que the acometeu graves queimaduras nos membros superiores e inferiores, impossibilitando-a de frequentar os anos primários da educação formal. Por conseguinte, mesmo sofrendo na escolarização, que desconhecia esse tipo de ocorrência à época e, portanto, como lidar com situações assim (BARBOSA, 2015), tornou-se uma pedagoga, psicanalista, jornalista e relações públicas de extensa atividade nas universidades do estado do Amazonas, além de produções literárias de prosa e verso (CAMELO, 2014; CNPq, 2018; FERREIRA; ROCHA, 2018; IERECÊ..., 2014).

Por sua vez, o colóquio foi ressignificado como estratégia formativa, enquanto produto educacional oriundo da pesquisa supracitada, na qual a etologia foi utilizada na triangulação da análise para averiguar a receptividade do conteúdo levado (nível formativo) para além dos filtros conscientes, ou não, dos participantes presentes nos registros escritos que foram analisadas à luz de Jung.

Assim, o colóquio como estratégia formativa foi construído com cinco momentos, preenchendo duas horas de atividade:

1. breve apresentação da pesquisa, da literatura-pretexto e sua autora (contexto e finalidade);

2. dinâmica do inconsciente coletivo, apresentação dos elementos junguianos trabalhados e as contribuições para a ciência pelo Círculo de Eranos (ilustrar e ressaltar potencialidades da abordagem);

3. sinopse da obra e sua análise (contribuições pedagógicas (auto)formativas) amparadas em pesquisas atuais que embasam a epistemologia de referência;

4. diálogo reflexivo;

5. momento do feedback (tempo para fazerem os registros escritos: emersão das unidades significativas).

A filmagem iniciou-se anteriormente ao debriefing, com nossa apresentação, e foi encerrada ao fim do colóquio, possibilitando a leitura das expressões das emoções também no momento de diálogo, próprio de colóquios.

Assim, a filmagem se configurou como Observação Direta Naturalística e Indireta (Não Reativa/Não Obstrutiva) de Traços Físicos (SHAUGHNESSY; ZECHMEISTER; ZECHMEISTER, 2012), já que foi analisada após a prática, em busca de evidências convergentes, ou não, com o registro escrito.

Esta opção foi adotada como complemento em Pesquisa Multimétodo em Tratamento Natural, nos termos de Flick (2009, p. 213): "[...] fatos de ocorrência natural, que impactam a sociedade ou indivíduos significativamente", haja vista que o conteúdo formativo foi 
embasado no Processo de Individuação de Carl Gustav Jung, por meio da Educação pelo Exemplo, também postulada por este autor.

Este tipo de abordagem tem sua validade na proposta da (auto)formação continuada como Pesquisa-formação, que também utiliza Biografia e Narrativas, e vê aprendente como aquele que escreve a partir de si e do reflexo do outro sobre si, pela revisitação de memórias, introjetando a percepção das influências sobre as escolhas que construíram a história de si. Que enquanto professores, se imbrica ao seu fazer docente, na sua relação com conteúdos, alunos, pares, posicionamentos, ideias, etc., pois "[a] [...] narração do passado é provocada e se elabora em torno de referências e de pontos em comum com a memória de outros." (BUENO et al., 1993, p. 304). É aquilo que Nóvoa (1993 apud CATANI; BUENO; SOUSA, 2000, p. 152) chama de autoaprendizado, que se soma ao aprendizado a partir da experiência do outro que nos recai, em um movimento dialógico para formação.

Tal percepção nos leva à Educação pelo Exemplo e ao Processo de Individuação de Jung a partir de elementos que vão de encontro aos arquétipos advindos do Inconsciente Coletivo e que a partir das experiências individuais podem emergir em forma de complexos ou para integralização do Self (JUNG, 1984, 2006). Exemplo disso é quando esse autor diz que: "[...] a síntese entre os conteúdos conscientes e inconscientes e a tomada de consciência dos efeitos dos arquétipos sobre os conteúdos conscientes representam o ponto máximo do esforço espiritual e da concentração das forças psíquicas." (JUNG, 1984, p. 215-216).

No nosso caso, não trazemos fotos por dois motivos: o anonimato assegurado no debriefing e pela análise da expressão das emoções obrigatoriamente ter que ser realizada em imagem dinâmica para que a leitura esteja sobre o início, ápice, decaimento e fim da expressão, além dos fatores de intensidade, de tempo de duração e de contexto, conforme os estudos de Ekman (2012) e instruções do Paul Ekman Group (2019). Porém, os vídeos foram analisados e aprovados em Banca Docente de avaliação da dissertação de mestrado da primeira autora.

Quanto à análise, houve expressão de nojo, surpresa, medo, alegria e tristeza, ante o contar a história de lerecê Barbosa, conforme o movimento da narrativa e os acontecimentos na vida da autora de $O$ Leilão e da protagonista do paradidático, projeção de várias situações da própria autora (GONÇALVES, 2020). O que é explicado pelo senso de empatia que evolutivamente o homem ancestral desenvolveu com seus pares, fortalecendo os laços de comunidade, como afirma Darwin (2009).

Observamos sinais de evitamento, de superioridade, de afastamento e não visualização, e de proteção quando o conteúdo-pretexto foi esmiuçado à luz da Psicologia Analítica, que aponta a decisão consciente pelo Processo de Individuação no indivíduo, como contribuição para desenvolvimento das potencialidades do ser (JUNG, 2000b, 2001, 2006). Isso justificado pela exigência desse movimento da energia psíquica quanto ao que podemos chamar de sair da zona de conforto, para experienciar e ressignificar a vida que levamos, e a que decidimos levar dali em diante.

Porém, como não nos dedicamos aqui a tratar dos postulados de Jung utilizados como epistemologia da nossa prática, nos dedicamos a trazer dois exemplos das possibilidades de verificação da receptividade ao conteúdo ministrado e da condição de aprendizagem do conteúdo, vistos o primeiro na primeira amostra e o segundo, na segunda. 
O primeiro reflete o comprometimento que horário e ideário podem conflitar na aprendizagem de conteúdos, haja vista que o primeiro impede que o aluno tenha contato com o conteúdo na íntegra e o segundo, decorrente também do primeiro, implica em filtros e freios que o aluno se impõe e que atrapalham a compreensão do que está sendo ministrado.

Frente aos textos, apenas esse registro escrito (Figura 1) não foi coincidente entre expressão e narrativa, porém a análise da linguagem e do comportamento não verbais apontaram inclusive os clusteres que indicavam aversão a momentos da preleção, assim como momentos de maior interesse, ainda que na escrita, o participante tenha exposto apenas o rejeite.

Assim, no primeiro caso, o participante, durante a filmagem, esboçou claros comportamentos de rejeite ao processo de individuação e ao vínculo que apresentamos entre este e o exercício docente por meio da Educação pelo Exemplo de Jung. Porém, revelou conflito entre aproximar-se e manter a posição de sentinela quando o conteúdo se referia aos elos familiares da protagonista de O Leilão e de lerecê Barbosa.

Figura 1 - Registro Escrito de participante da amostra menor

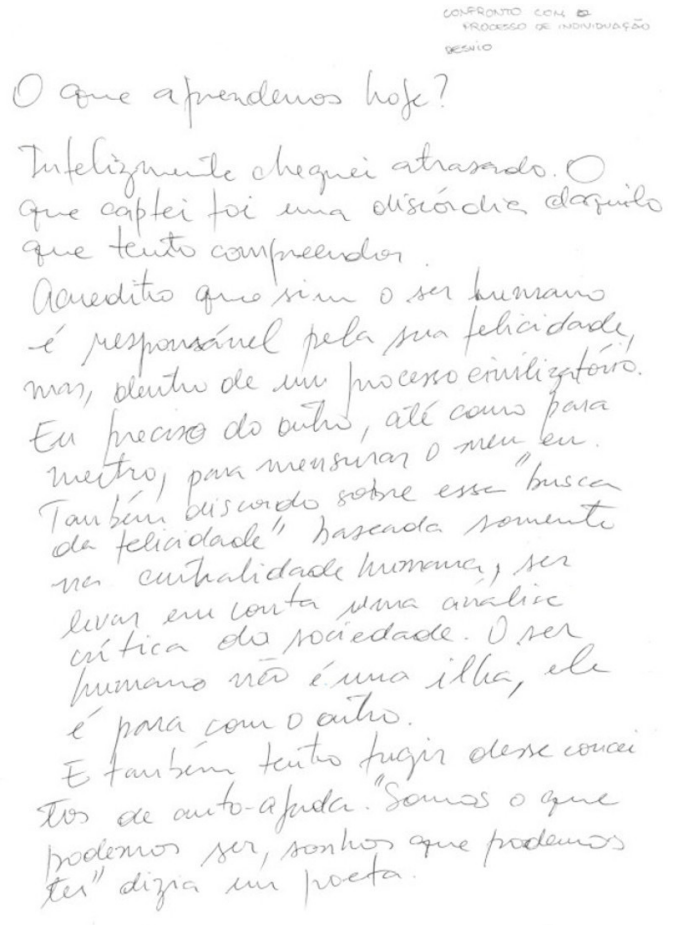

Fonte: elaborado pelos autores a partir de dados da pesquisa.

Em um cenário de sala de aula (mais prolongado que o de um colóquio) esses aspectos seriam levados em conta para contornar esse rejeite e acolher o participante, a fim de aproximá-lo de compreender a proposta junguiana - ainda que não a aceitasse - para não realizar julgamentos superficiais quanto ao conteúdo mediado, como por exemplo, incentivar a chegada em tempo hábil para a aula, e entrosamento maior em aulas dialogadas, partilhando a percepção dos demais alunos.

$\mathrm{Na}$ amostra maior, não houve uma rejeição declarada, nem houve tantos comportamentos de evitação ou superioridade, mas de proteção e desconforto ante a alguns conteúdos da preleção; assim como momentos de enjoyable emotions extremamente visíveis, aliadas a comportamento de interesse em momentos de nossa fala. 
Estas reações emocionais foram ainda evidenciadas na escrita - materialmente falando -, pois em ao menos um dos registros (Figura 2), a tensão na musculatura influenciou o processo de escrita quanto à forma e apresentação, assim como no processo cognitivo de filtros e escolhas de conteúdo a revelar, o que à luz da Psicologia Analítica também nos rendeu conteúdo dos quais não nos ocupamos no escopo deste trabalho.

Eis o segundo caso que aponta para níveis superficiais de compreensão do conteúdo, barrados por forte descarga emocional que poderia ser a pari passu vencida no decorrer do convívio em sala de aula através dos conteúdos que ali caberiam a espaços maiores de discussão, e dali a possibilidade de uma compreensão mais aprofundada do conteúdo.

Figura 2 - Registro Escrito de participante da amostra maior [contendo anotações quanto a Unidades Significativas, não pertencentes ao escopo deste trabalho].

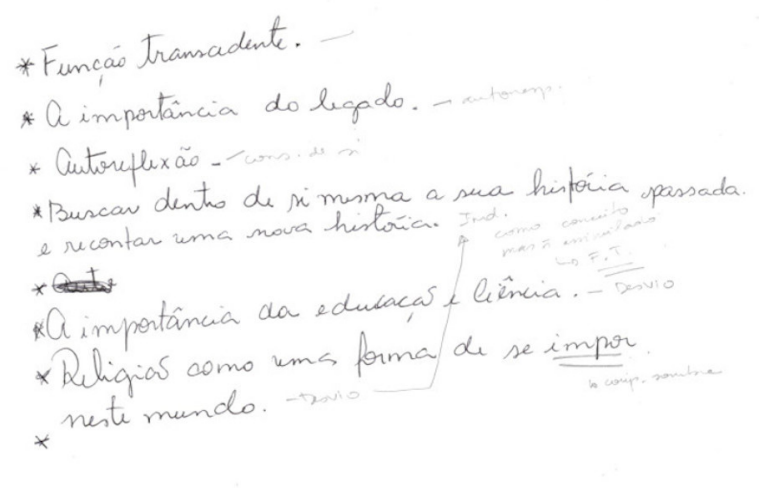

Fonte: elaborado pelos autores a partir de dados da pesquisa.

O leitor pode observar a alteração da linha de base da escrita que se apresenta, com elevações, alteração no tamanho das letras e atribuição de letras maiúsculas sem correlação com o contexto, e fora da linha de base do texto. Inferimos que o conteúdo teve tal carga emocional para esta pessoa que a descarga emocional consequente influenciou tanto no processo cognitivo de elaboração do texto, quanto da apresentação ortográfica.

Destacamos para que o leitor observe a retração ou expansão da escrita ainda, além de curvas e aclives no texto. Aumento e diminuição dos caracteres, reforço sobre alguns asteriscos e a ausência da escrita final, após uma visível alteração da palavra que inicia o penúltimo ponto elencado, que veio a ser o último pela ausência do seguinte.

Dentro do contexto de uma aula integrante de conteúdo curricular, outras unidades latentes de sentido emergiriam a partir de uma escrita que se assemelhasse a esta, o que aponta a consistência de considerar o protocolo $A B C$ descrito anteriormente.

De qualquer forma, o essencial é que a leitura do comportamento e da linguagem não verbais indicaram que era uma situação a ser trabalhada por abordagens outras em sala de aula, a fim de promover uma melhor mediação de ensino e de aprendizagem para aquele(a) participante.

Esses são dois exemplos que consideramos encontrar quando pensamos no uso da Etologia (Biologia do Comportamento) como possibilidade de triangulação do que averiguávamos na ocasião, que descerram o véu sobre as possibilidades do uso da leitura da linguagem e do comportamento não verbais como estratégia docente para mediação do ensino e da aprendizagem com os discentes. 
Apontamos para as potencialidades de uso para resolver desde questões interferentes ao processo da sala de aula, até para pensar e desenvolver estratégias outras de abordagem de conteúdo, a fim de promover maior acesso dos alunos aos conteúdos ministrados.

A compreensão do efeito das emoções nos lança, enquanto docentes, a vermos a relação com nossos alunos de maneira mais humanizada e desenvolvermos, em nós mesmos e neles, potenciais de mediação e interação mais proveitosos coletivamente, e que subsidiem o reforço nos laços de percepção de comunidade tão necessários para vencermos as barreiras ideológicas que se afiguram no cenário social brasileiro nos dias em curso.

\section{Reflexões}

Como está sendo dito desde Darwin (2009) até Ekman e seus colaboradores (EKMAN, 2012; EKMAN; FRIESEN, 2003; EKMAN; ROSENBERG, 2005; LANSLEY, 2017; NAVARRO; KARLINS, 2008), as emoções são um processo que pode alterar a nossa percepção de bemestar, não sendo ininterrupto (não somos emocionais em tempo integral), ainda são inatas e universais, observadas externamente pelas expressões musculares. Haja vista o processo fisiológico desencadeado ante o evento que dá início à reação, com início nos mecanismos hormonais de resposta ao estímulo/gatilho, e manifesto através dos músculos envolvidos em diversas áreas do corpo (Sistema Nervoso Autônomo) (BOISVERT, 2019; DARWIN, 2009; EKMAN, 2012) para nos aproximarmos do evento (felicidade, surpresa), ou nos afastarmos dele (medo, raiva, nojo, tristeza, surpresa).

Causa pela qual as emoções podem ser identificadas externamente (CUDDY, 2016; DARWIN, 2009; EKMAN, 2012; EKMAN; FRIESEN, 2003; EKMAN; ROSENBERG, 2005; LANSLEY, 2017; NAVARRO; KARLINS, 2008):

a. pela condição cardiorrespiratória;

b. pela postura corporal: ambas manifestarão movimentos musculares involuntários consequentes da aceleração do bombeamento cardíaco e do volume no fluxo sanguíneo nos membros e outras partes do corpo como ombros, pescoço, torso;

c. pela face: como a não visualização, além da musculatura facial;

d. pela alteração vocal: também afetada pelos fatores hormonais e consequentemente reflexos musculares;

e. e/ou pela sudorese e temperatura corporal.

Todos esses são canais fisiológicos que podem ser analisados no protocolo SCAns, sendo dirigidos pelo sistema nervoso autônomo, que por sua vez, é diretamente afetado pelas emoções, sem que tenhamos controle sobre seus reflexos, dado o tempo da ação primária da hipófise, seguida pelas glândulas anexas, em feedback (EKMAN, 2012).

As percepções sobre o processo sistêmico ativado ante as emoções já eram apontadas por Darwin (2009), incluindo o fluxo de canais (protocolo SCAns) por onde será expressa a emoção:

Consequentemente, os músculos faciais e respiratórios, que são os mais utilizados, estarão entre os primeiros a ser acionados; em seguida os das extremidades superiores, depois os das inferiores, e finalmente o corpo todo. [...] quando movimentos são desencadeados, sua natureza é largamente determinada por aqueles movimentos que foram voluntária e frequentemente executados, com algum objetivo definido, sob as mesmas emoções. [...] Como os músculos do tórax e dos órgãos vocais são habitualmente usados, há sempre uma tendência para que sejam acionados [...] (DARWIN, 2009, p. 68). 
No geral, podemos concluir que o princípio da ação direta do sensório sobre o corpo, devido à constituição do sistema nervoso, e desde o início independente da vontade, influenciou muito a determinação de muitas expressões. Bons exemplos são o tremor dos músculos, o suor da pele, a modificação na secreção do canal e das glândulas alimentares, em diferentes emoções e sensações. [...] Mesmo quando essas e outras sensações e emoções foram apenas levemente despertadas, persistirá uma tendência a ações similares, graças à força de um hábito longamente associado [...]. (DARWIN, 2009, p. 76).

Esse fluxo emocional, tal qual o inconsciente coletivo junguiano, herança ancestral remota ao aparecimento da humanidade no planeta, anterior ao estabelecimento do comportamento social, foi neste último imerso: já não nos aproximamos e nos afastamos só do que salva e mantém nossas vidas ou sustenta a continuação dos nossos genes pela prole.

Porém, imiscuiu-se de tantas outras situações que, atualmente, podem ser terrificantes, como por exemplo, uma situação estressante no trabalho ou uma "fechada" no trânsito, que não estão atreladas somente à sua manifestação de realidade física, mas podem ser tão concretas do ponto de vista psíquico quanto o que podem corresponder a um arquétipo (JUNG, 2000a).

Como o medo do escuro ou do que pode parecer ameaçador, ainda que depois se verifique ser, por exemplo, um animal artificial, mas de aparência muito realista. Neste ponto, Darwin (2009) reforça a ação psíquica sobre a condição fisiológica:

[...] sempre que qualquer sensação de desejo, aversão, etc. tenha ocasionado algum movimento voluntário durante uma longa série de gerações, uma tendência à execução de movimento similar será quase certamente desencadeada toda vez que a mesma - ou semelhante e associada - sensação etc., ainda que fraca, for experimentada; não importando que o movimento seja nesse caso absolutamente inútil. Tais movimentos habituais são frequentemente, ou no geral, herdados; e eles assim pouco diferem das ações reflexas. [...] quando movimentos, associados pelo hábito a certos estados de espírito, são parcialmente reprimidos pela vontade, os músculos exclusivamente involuntários, como também aqueles menos submetidos ao controle da vontade, tendem a continuar agindo. E sua ação é frequentemente muito expressiva. Ao contrário, quando a vontade está temporária ou permanentemente enfraquecida, os músculos voluntários cedem antes dos involuntários. (DARWIN, 2009, p. 48).

Assim, para o Homo sapiens sapiens, a realidade e a realidade psíquica se complementam, não pedindo autorização do indivíduo, nem que ele tenha consciência dela, o que explica que o mesmo evento seja, ou não, gatilho para indivíduos diferentes.

O que Ekman (2012) chama de "species-constant learning or evolution", que vemos se aproximar do inconsciente coletivo de Jung (1984), assomam aos gatilhos universais de ameaças ao bem-estar físico individual e da espécie, alimentado e mantido a cada experiência individual e coletiva, além das experiências ancestrais, e se atualizando com os novos riscos, como os novos vírus que assolam esses dias.

Porém, Ekman e Jung corroboram McAdams e McLean (2013) quanto ao poder de influência de reviver e recontar a si mesmo sua história, dirimindo o que realmente deve ser mantido afastado ou ser aproximado do que é reflexo obscurecido da memória, pela descarga emocional na ocorrência do fato que acentuou ou declinou as margens reais do episódio e do valor a ele atribuído. 
Este movimento exógeno é sustentado pelos estudos de Cuddy $(2012,2016)$ sobre as alterações bioquímicas no corpo a partir de uma nova postura adotada, a ponto de respostas hormonais significativas em exames laboratoriais com 2 (dois) minutos de exposição.

Assim, temos que o tratamento que damos às emoções é extremamente significativo para nos fortalecer enquanto indivíduos e também ao nosso senso de comunidade e coletividade, e, desse modo, merecedor de mais aprofundados estudos e práticas que os testem e os evidenciem.

De forma que a sala de aula seja, enquanto laboratório do professor pesquisador e espaço para o exercício não só da pesquisa-formação, também da humanização do exercício docente e das relações discentes, a fim de mitigar conflitos que não são apenas dos nossos alunos, mas que reverberam em maiores proporções como conflitos da sociedade.

É prioritário que nós comecemos este (auto)gerenciamento para contribuirmos com uma sociedade mais empática e acolhedora a todos.

A experiência de utilizar a ciência da leitura das expressões emocionais nestas duas amostras evidenciou pela linguagem e pelos comportamentos não verbais da maioria preponderante, corroborado pelos registros escritos, que olhar para si através e a partir do outro são chaves para reflexões de busca de (auto)formação, a fim de nos tornarmos pessoas melhores e por conseguinte, profissionais mais preparados para ver o outro e não apenas lidar com ele a partir da hierarquia e da construção social.

\section{Considerações Finais}

Neste trabalho consideramos apenas que o leitor entreveja as possibilidades e potenciais de trazer a Biologia do Comportamento para as estratégias docentes de mediação em sala de aula. Desta forma, trabalhamos esse recorte de nossa pesquisa aprovada no mestrado em Ensino, para que se apresentasse como um olhar que nasceu do que era apenas uma ferramenta para triangulação para nos afigurar como uma aliada na docência.

Assim, contamos uma experiência pura e simples em uma aula e reforçamos com dois casos ocorridos em atividades de extensão que desenvolvemos para responder à problematização que realizamos sobre o valor das questões, que são muitas vezes ignoradas e desmerecidas na prática docente, como as emoções dos participantes do processo.

Neste sentido, reunimos uma visão geral e ampla dos contributos da ciência deste escopo, onde se destaca Paul Ekman que por sua vez dirige a Charles Darwin o pontapé neste campo da relação das respostas biológicas a situações práticas e psicológicas que acometem o Homo sapiens, o que nos dá uma janela temporal de praticamente uma centena de anos, corroborada ainda na atualidade pelos avanços das tecnologias de verificação da fisiologia humana. Que sabemos, não é suficiente para adensar o conteúdo, mas se propõe a despertar o interesse dos leitores para a literatura ampla que aborda a temática.

Ainda respingamos um pouco da psicologia analítica de Jung para localizar o Homo sapiens sapiens que é somatizado fisiologicamente por gatilhos emocionais desconhecidos de seus ancestrais, mas que tomam a mesma proporção de impacto que evitar o dano a fim da sobrevivência e manutenção de si e da espécie.

Ilustramos, assim, essa importância através de três experiências, uma em sala de aula e as demais em atividades de extensão, porém, com fins docente-pedagógicos, revelando as potencialidades que emergiram a partir da leitura etológica realizada, e os direcionamentos 
tomados ou possíveis de serem desenvolvidos, para os exemplos em tela e que apenas são uma antevisão de outras possibilidades, com o uso da biologia do comportamento na docência.

Encerramos trazendo reflexões que endossam o papel das emoções, de forma que a promoção da atenção a elas, permite um (auto)gerenciamento que pode contribuir para relações mais harmoniosas entre professores e alunos. E, daí, para a comunidade, fortalecendo os laços do coletivo, superando barreiras ideológicas pela empatia, pela compreensão, e redirecionando atitudes, para que o conhecimento se amplie e se aprofunde, porque antes de ser aquele que ministra o conteúdo, somos o humano lidando com outros humanos.

\section{Agradecimentos}

Agradecemos à Fundação de Amparo à Pesquisa do Estado do Amazonas, pelo fomento à pesquisa de origem (062.00840/2019).

\section{Referências}

BARBOSA, I. S. O leilão. Curitiba: Appris, 2015.

BOISVERT, H. How I'm using biological data to tell better stories and spark social change. New York: TED Ideas worth spreading, 2019. Disponível em: https://cutt.ly/TgewHIZ. Acesso em: 12 dez. 2019.

BUENO, B. O.; SOUSA, C. P.; CATANI, D. B.; SOUZA, M. C. C. C. Docência, memória e gênero: estudos alternativos sobre a formação de professores. Psicologia USP, São Paulo, v. 4, n. 1-2, p. 299-318, 1993. Disponível em: https://cutt.ly/Lgew96M. Acesso em: 6 out. 2020.

CAMELO, L. Professora lerecê Barbosa lança romance paradidático em contextos amazônicos. acritica.com, Manaus, 1 jul. 2014. Disponível em: https://cutt.ly/ugew42J. Acesso em: 13 jan. 2019.

CATANI, D. B.; BUENO, B. A. O.; SOUSA, C. P. "O amor dos começos"': por uma história das relações com a escola. Cadernos de Pesquisa, São Paulo, n. 111, p.151-171, 2000. DOI: https://doi.org/ddzpzz.

CNPQ. Currículo Lattes: [lerecê dos Santos Barbosa]. Brasília: CNPq, [2018]. Disponível em: http:// lattes.cnpq.br/7671831772363755. Acesso em: 26 set. 2018.

CUDDY, A. O poder da presença. Rio de Janeiro: Sextante, 2016.

CUDDY, A. Sua linguagem corporal molda quem você é. Edinburgh: TED ideas worth spreading, jun. 2012. Disponível em: https://cutt.ly/KgeewiQ. Acesso em: 22 out. 2019.

DARWIN, C. A expressão das emoções no homem e nos animais. São Paulo: Companhia das Letras, 2009.

EKMAN, P. Emotions revealed: understanding faces and feelings. London: Weidenfeld \& Nicolson, 2012.

EKMAN, P.; FRIESEN, W. V. Unmasking the face. Los Altos: Malor Books, 2003.

EKMAN, P.; ROSENBERG, E. L. What the face reveals: basic and applied studies of spontaneous expression using the facial action coding system (FACS). 2. ed. Oxford: Oxford University Press, 2005.

FERREIRA, A.; ROCHA, I. J. Memórias: entrevista com lerecê Barbosa. Conexões: revista de relações públicas e comunicação organizacional, Manaus, v. 1, n. 1, p. 81-87, 2018. Disponível em: https:// www.periodicos.ufam.edu.br/conexoes/article/view/3891. Acesso em: 6 out. 2020. 
FLICK, U. Qualidade na pesquisa qualitativa. Porto Alegre: Artmed, 2009.

GONÇALVES, C. E. L. C. Um estudo em lerecê Barbosa: as contribuições pedagógicas em "o leilão". 2020. Dissertação (Mestrado Profissional em Ensino Tecnológico) - Instituto Federal de Educação, Ciência e Tecnologia do Amazonas, Manaus, 2020.

IERECÊ Barbosa e o misterioso homem que jantava sozinho. D24am, Manaus, 16 dez. 2014. Disponível em: http://d24am.com/plus/ierece-barbosa-e-o-misterioso-homem-que-jantavasozinho/. Acesso em: 13 jan. 2019.

JUNG, C. G. Os arquétipos e o inconsciente coletivo. Petrópolis: Vozes, 2000a.

JUNG, C. G. O desenvolvimento da personalidade. 9. ed. Petrópolis: Vozes, 2006.

JUNG, C. G. A dinâmica do inconsciente. Petrópolis: Vozes, 1984.

JUNG, C. G. Fundamentos de psicologia analítica: primeira conferência. Petrópolis: Vozes, 2001.

JUNG, C. G. A natureza da psique. Petrópolis: Vozes, 2000b.

LANSLEY, C. Getting to the truth: a practical, scientific approach to behavior analysis for professionals. Manchester: Emotional Intelligence Academy, 2017.

McADAMS, D. P.; McLEAN, K. C. Narrative identity. Current Directions in Psychological Science, UK, v. 22, n. 3, p. 233-238, 2013. DOI: https://doi.org/10.1177/0963721413475622.

NAVARRO, J.; KARLINS, M. What every body is saying: an ex-FBI agent's guide to speed-reading people. New York: William Morrow, 2008.

PAUL EKMAN GROUP LLC. Paul Ekman group. [2019]. Disponível em: https://www.paulekman.com/. Acesso em: 11 set. 2019.

SHAUGHNESSY, J. J.; ZECHMEISTER, E. B.; ZECHMEISTER, J. S. Metodologia de pesquisa em psicologia. 9. ed. Porto Alegre: AMGH, 2012. 